\title{
FICÇÕES DE ESCRITORES FICTÍCIOS
}

\author{
Claudia Maria Pereira Almeida* \\ Universidade do Estado do Rio de Janeiro
}

Resumo: O autor vem sendo objeto de estudo desde que sua existência foi reconhecida. Ao longo do tempo, seu papel na sociedade e na construção do texto literário receberam diferentes matizes. Na segunda metade do século XX, seu desaparecimento foi anunciado como necessário para que o texto se abrisse a múltiplos sentidos construídos pelo leitor. Embora a noção de autor nunca tenha se desvanecido, na literatura contemporânea podemos observar sua presença recorrente no tecido textual na forma de autores-personagens. Dentre as várias formas em que se apresenta, destacamos duas que compartilham a natureza fictícia, mas trilham caminhos bastante diferentes nos fios do texto: Eckermann, em Le Coeur de Marguerite (1999), de Vassilis Alexakis, e Émile Ajar, em Pseudo (1976), de Romain Gary. Transformado em elemento da ficção, o autor adquire novos sentidos e suscita novas reflexões sobre o que é um autor.

Palavras-chave: Vassilis Alexakis. Romain Gary. Autor. Ficção contemporânea.

Eu sabia que era fictício e então pensei que talvez eu tivesse jeito para a ficção. (GARY/AJAR, 1976) $^{1}$

\section{Idas e vindas do autor}

A definição do papel do autor do texto literário vem sendo discutida desde o seu reconhecimento enquanto tal. O itálico utilizado na palavra confirma a pluralidade de sentidos que o termo abarca e, consequentemente, a complexidade de análise de sua conceituação e de suas configurações. Assim, entre os extremos da solidez de suas intenções e do banimento da busca de seus intuitos, o autor se mantém como objeto de estudo.

$\mathrm{Na}$ França, a questão do autor é particularmente estudada pela crítica literária ao longo do século XX. Nos anos 1960, a conclusão do ensaio célebre de Roland Barthes (1968)

\footnotetext{
* Doutora em Letras Neolatinas pela Universidade Federal do Rio de Janeiro (2004). Atualmente é professora de Língua e Literatura Francesa da Universidade do Estado do Rio de Janeiro e professora de ensino fundamental e médio de língua francesa do Colégio Pedro II. No campo dos estudos literários, pesquisa principalmente questões ligadas à alteridade, ao bilinguismo, aos deslocamentos e migrações, à estrangeiridade e às construções de ethos. E-mail: cmp.almeida@yahoo.com.br.

${ }^{1}$ Salvo indicação na bibliografia, as traduções foram feitas por mim e os originais serão indicados em nota de rodapé. Je savais que j'étais fictif et j'ai donc pensé que j'étais peut-être doué pour la fiction.
}

Anu. Lit., Florianópolis, v. 19, n. 2, p. 9-23, 2014. ISSNe 2175-7917 
sobre o assunto - "o nascimento do leitor deve ser pago com a morte do Autor" ${ }^{2}$ - destaca uma discussão importante para a nova crítica francesa: era preciso liberar o texto de uma autoridade preestabelecida e assegurar a liberdade de construção de sentidos por parte do leitor. A morte de um certo autor - aquele que possuía e controlava os segredos da origem afasta o foco da escolha da combinação entre urdidura e trama no tear e o aproxima do tecido produzido. Dessa forma, um certo leitor - aquele que busca seguir fios e perceber cores e texturas - assume o papel de produtor de sentidos que se entrecruzam reconstruindo o tecido.

Mas o autor não desaparece totalmente dos estudos literários. No ano seguinte à publicação do texto de Barthes, em uma conferência no Collège de France, Michel Foucault atenua a morte anunciada identificando uma "função" autor desprovida de uma autoridade prévia que serviria de balizamento para a leitura, mas fiadora do reconhecimento de um determinado discurso:

Ele [o nome do autor] manifesta a ocorrência de um certo conjunto de discurso, e refere-se ao status desse discurso no interior de uma sociedade e de uma cultura. $\mathrm{O}$ nome do autor não está localizado no estado civil dos homens, não está localizado na ficção da obra, mas na ruptura que instaura um certo grupo de discursos e seu modo singular de ser. (FOUCAULT, 2009, p. 274)

A função autor garante, entre outros, o caráter permanente de um discurso, contrariamente à palavra quotidiana "consumível" que se esvai sem uma recepção definida. Ainda segundo Foucault, uma das características dessa função é a pluralidade de egos, ou seja, não se refere a um indivíduo real, mas sim à pluralidade de "posições-sujeitos".

Antoine Compagnon também se debruça sobre a questão do autor e identifica, nos textos de Barthes e Foucault, uma redução do "autor biográfico ou sociológico, significando um lugar no cânone histórico, com o autor, no sentido hermenêutico de sua intenção, ou intencionalidade, como critério da interpretação" (COMPAGNON, 2012, p. 52) Compagnon conclui que a intenção, na verdade, não pode ser banida pois faz parte da construção do texto e do processo de leitura:

Assim, para muitos filósofos contemporâneos, não cabe distinguir intenção do autor
e sentido das palavras. O que interpretamos quando lemos um texto é,
indiferentemente, tanto o sentido das palavras quanto a intenção do autor. Quando se
começa a distingui-los, cai-se na casuística. Mas isso não implica a volta ao homem
e à obra, uma vez que a intenção não é o objetivo e sim o sentido intentado.
(COMPAGNON, 2012, p. 91)

No campo da análise do discurso, Dominique Maingueneau, retomando Foucault, apresenta o autor como uma categoria híbrida que se refere simultaneamente "ao texto e ao

\footnotetext{
${ }^{2}[\ldots]$ la naissance du lecteur doit se payer de la mort de l'Auteur.
} 
mundo do qual esse texto participa". (MAINGUENEAU, 2010, p. 26) O linguista aponta três dimensões da noção de autor: o autor-responsável, que não é especificamente literário, mas tão somente aquele que assina o texto; o autor-ator, que organiza e administra sua carreira; e o auctor, aquele que se constitui a partir de um Opus e cuja imagem é construída por terceiros. Esta terceira dimensão se subdivide em três instâncias: a pessoa, ou seja, o indivíduo que tem um registro civil; o escritor, aquele que atua no campo literário; e o inscritor, que assume as funções de enunciador e de agenciador do texto. (MAINGUENEAU, 2010b)

A partir, principalmente, das propostas teóricas de Pierre Bourdieu e Dominique Maingueneau, Jérôme Meizoz desenvolve a noção de postura como a "maneira singular de ocupar uma posição no campo literário."3 (MEIZOZ, 2007, p. 18). Retomando a discussão sobre o autor, o escritor e crítico suíço destaca a articulação entre os planos retórico e sociológico dessa noção: por um lado, todos os discursos orais e escritos emitidos pelo autor contribuem para a formação de uma imagem; por outro, as atitudes corroboram ou contradizem os discursos e, por isso, também participam dessa imagem. Meizoz ainda salienta o caráter plural da autoralidade do livro:

\begin{abstract}
Na prática, estamos diante de uma auctorialidade plural. Um processo coletivo está no segundo plano da gênese textual: o autor certamente, mas também o editor, as instituições diversas que podem intervir no projeto de escrita (para obtenção de ajuda de um mecenas, de uma bolsa etc.), a gráfica e o tipógrafo, cujas intervenções decisivas nas peças de Molière foram mostradas por Roger Chartier (1996), por exemplo. Sem contar, hoje, os agentes literários que exigem os roteiros das obras que devem promover, releem os manuscritos etc. ${ }^{4}$ (MEIZOZ, 2007, p. 24-25)
\end{abstract}

A identificação de um conjunto de participações de diversos agentes no produto final que chega às mãos do leitor concorre para confirmar a dessacralização do autor e, consequentemente, sua morte enquanto instância maior detentora dos sentidos do texto. $\mathrm{O}$ caráter plural do autor não determina, contudo, seu desaparecimento.

Cinco anos após a publicação de "A morte do autor", Roland Barthes retoma a questão e concede ao morto a possibilidade de ser desejado:

Como instituição o autor está morto: sua pessoa civil, passional, biográfica, desapareceu; desapossada, já não exerce sobre sua obra a formidável paternidade que a história literária, o ensino, a opinião tinham o encargo de estabelecer e de renovar a narrativa: mas no texto, de uma outra maneira eu desejo o autor: tenho

\footnotetext{
${ }^{3}$ La "posture" est la manière singulière d'occuper une "position" dans le champ littéraire.

${ }^{4}$ Dans la pratique, c'est à une auctorialité plurielle que l'on a le plus souvent affaire. Un processus collectif est à l'arrière-plan de la genèse textuelle: l'auteur certes, mais aussi l'éditeur, les institutions diverses qui peuvent intervenir sur le projet d'écriture (pour obtention d'une aide mécénale, d'une bourse, etc.), l'imprimeur et le typographe, dont Roger Chartier (1996) a montré les interventions décisives sur les pièces de Molière, par exemple. Sans compter, aujourd'hui, les agents littéraires qui exigent à l'avance des scripts d'ouvrages à promouvoir, relisent les manuscrits, etc.
}

Anu. Lit., Florianópolis, v. 19, n. 2, p. 9-23, 2014. ISSNe 2175-7917 
necessidade de sua figura (que não é nem sua representação nem sua projeção) tal como ele tem necessidade da minha (salvo no tagarelar). (BARTHES, 1996, p. 38)

Na literatura contemporânea, sobretudo na narrativa, esse desejo parece se manifestar através de uma profusão de personagens de autor. Com características ou em situações fictícias, como confidente do narrador ou de um personagem, como destinatário explícito ou não, enfim, em um grande leque de configurações o personagem autor marca presença na ficção. Embora esse procedimento não seja uma criação recente, pode-se perceber uma recorrência significativa no romance contemporâneo da 'autorreflexividade, a presença do escritor em sua mesa, suas crises e suas dificuldades no trabalho de criação". (FIGUEIREDO, 2013, p. 14)

Neste texto, estudaremos dois exemplos de resgate do autor através do personagem. O primeiro apresenta um autor fictício que remete a outro, do século XVIII. Trata-se de Eckermann, em Le Coeur de Marguerite (1999), de Vassilis Alexakis. O segundo texto, Pseudo (1976), de Romain Gary, estabelece um vertiginoso jogo de espelhos ao apresentar um real escritor fictício.

\section{Escritor fictício}

Na obra literária de Vassilis Alexakis, a cena de enunciação em que um escritor narra a escrita de seu livro é recorrente. Em alguns textos, o narrador é escritor, em outros quer começar uma carreira literária, em outros ainda decide escrever um artigo científico ou uma experiência pessoal. O próprio autor explica essa escolha:

Prefiro ter o problema tal como o vivo: há um narrador. Não sou eu, mas um personagem como os outros, um personagem fabricado, a não ser pelo fato de que esse narrador escreve. [...] Um dos grandes temas, além da morte e das línguas, é a escrita. A dificuldade de escrever retorna o tempo todo. A respeito desse assunto, sou inesgotável. ${ }^{5}$ (ALEXAKIS apud BESSY, 2011, p. 250)

O personagem escritor, que também é o narrador, recoloca em cena o autor, explicitando discussões sobre o ato de escrever e apresentando o contexto de composição do texto e a vida quotidiana de quem escreve. Dessa forma, o autor ganha uma nova existência dentro da ficção.

Entretanto, em Le Coeur de Marguerite (1999), além desse narrador (candidato a) escritor, há outro personagem, Eckermann, escritor ele também, que desempenha importante papel no processo de escrita do narrador.

\footnotetext{
${ }^{5}$ Je préfère avoir le problème tel que je le vis: il y a un narrateur. Ce n'est pas moi mais un personnage comme les autres, un personnage fabriqué, sauf que ce narrateur est censé écrire. [...] Un des grands thèmes, à part la mort et les langues, c'est l'écriture. La difficulté d'écrire revient tout le temps. Sur ce sujet, je suis intarissable.
} 
No texto de Alexakis, Eckermann é um escritor alemão cuja família emigrou para os Estados Unidos. Todos os seus livros eram escritos em inglês. O narrador, cujo nome jamais é mencionado, cita títulos e trechos, resume intrigas e faz comentários dessa obra. Desde o início, Eckermann é seu modelo: "Sonho com um texto capaz de multiplicar os espaços de minha vida, de me dar a mesma sensação que eu tinha quando, criança, lia Júlio Verne e Alexandre Dumas e que experimento com a leitura de Eckermann." (ALEXAKIS, 1999, p. 8) Esse é o escritor que o impressiona no presente e cujas habilidades ele tenta desenvolver.

O escritor fictício ocupa, assim, o lugar de referência e de desejo: mais do que o mestre a seguir, trata-se de ser (como) Eckermann. Na enumeração, ao lado de Júlio Verne e Alexandre Dumas, escritores reais, Eckermann ganha consistência e leva o leitor a se perguntar se está realmente diante de uma criação ou se o homônimo do secretário de Goethe tem vida fora do texto alexakiano.

A referência ao escritor do século XIX, Johann Peter Eckermann, é explícita e nem um pouco aleatória. $\mathrm{O}$ narrador, porém, não o conhecia; é seu homônimo que lhe sugere a leitura do texto célebre:

- O senhor deveria ler as Conversações com Goethe, de Eckermann, me aconselhou. $[\ldots]$

Quem era esse outro Eckermann cujo nome eu ouvia pela primeira vez? Confessei minha ignorância ao escritor.

- Era um admirador de Goethe, que transcrevia com exatidão todas as falas do poeta. Ele não perdia nem uma migalha. Sabia escutar. ${ }^{7}$ (ALEXAKIS, 1999, p. 204205)

Mesmo sem ter lido o livro, o narrador decide seguir o mesmo percurso; "Eu também tentarei reproduzir fielmente o que o senhor disse esta noite, lhe prometi." (ALEXAKIS, 1999, p. 205)

Os trechos citados reproduzem a primeira conversa real que estabelecem escritor e narrador. Eckermann vai à capital da ilha de Andros fazer uma conferência e seu admirador não poupa esforços para assisti-la e para conversar com o escritor. Até esse momento, as conversas eram imaginárias e as reações atribuídas a Eckermann quimeras produzidas pelo narrador. $\mathrm{O}$ encontro pessoal entre ambos não apenas confirma as expectativas do narrador, mas também revela um escritor bastante solícito com um leitor que conhece bem sua obra.

\footnotetext{
${ }^{6}$ Je rêve d'un texte susceptible de multiplier les espaces de ma vie, de me donner la même sensation de liberté que j'avais enfant, en lisant Jules Verne et Alexandre Dumas, et que j'éprouve à la lecture d'Eckermann.

${ }^{7}$ Vous devriez lire les Conversations de Goethe avec Eckermann, m'a-t-il conseillé.

Qui était cet autre Eckermann dont j'entendais parler pour la première fois? J'ai confessé à l'écrivain mon ignorance.

- C'était un admirateur de Goethe, qui transcrivait avec exactitude tous les propos du poète. Il n'en perdait pas une miette. Il savait écouter.

${ }^{8}$ - Je tâcherai moi aussi de reproduire fidèlement ce que vous avez dit ce soir, lui ai-je promis.
} 
Após a conferência, o narrador o convida para jantar e, diante da hesitação do agente que organizara o evento, o escritor responde: "Escute, disse, esse senhor se deu ao trabalho de encontrar o trecho de música que eu tinha em mente ao terminar um de meus livros. Não posso recusar seu convite. Há coisas, senhor Galanos, que um poeta como o senhor pode compreender. Venha conosco se quiser." (ALEXAKIS, 1999, p. 197)

Eckermann age como o narrador esperava. Eckermann é como ele esperava que fosse. A partir desse jantar, pode-se dizer que uma amizade entre pares tem início. $\mathrm{O}$ principiante na literatura fala de sua relação com Marguerite e do livro que está escrevendo. $\mathrm{O}$ escritor ouve atentamente e dá sugestões em relação aos dois assuntos. Tal como um amigo compreensivo e experiente, Eckermann o encoraja a não desistir nem da mulher amada nem do texto que se arrasta sem término. Como incentivo para vencer as dificuldades que o narrador relata, o escritor declara: "As palavras conhecem todas as histórias, mas as esquecem. Elas já sabem tudo sobre o que escrevemos. Nós apenas refrescamos a memória das palavras." $" 10$ (ALEXAKIS, 1999, p. 255)

Em Le Coeur de Marguerite, a presença do escritor fictício nos faz pensar em alguns aspectos da noção de autor. Em primeiro lugar, a intenção do autor se confunde com a construção da obra. Insatisfeito com seu trabalho de cineasta, especialista em documentários, o narrador decide pôr em prática um projeto recalcado: dedicar-se à escrita de um livro. Confessando não ter um tema, pensa na possibilidade de escrever sobre seu relacionamento com Marguerite: “O que eu vou fazer se minha relação com Marguerite terminar no meio do primeiro capítulo, ou até no fim do segundo? Será que deveria encontrar outra heroína? Na verdade, não tenho assunto."11 Esse escritor principiante busca, pois, não apenas realizar o desejo que o acompanha desde a infância, mas também narrar sua própria história.

Em nenhum momento, o narrador discute o caráter ficcional ou não de seu texto. Como vemos no trecho citado, o livro parece estar fortemente ligado à realidade que vive seu autor no momento da escrita. A intenção, reproduzir o real, é apresentada naturalmente. $\mathrm{O}$ documentarista abandona a câmera e assume a pena, o olhar cede lugar à escrita, mas o procedimento é semelhante: retratar um fragmento da realidade.

Esse caráter documental é reforçado por uma construção em patchwork:

\footnotetext{
${ }^{9}$ Écoutez, lui a-t-il dit, ce monsieur s'est donné la peine de trouver l'air de musique que j'avais en tête en terminant un de mes livres. Je ne peux pas refuser son invitation. Il y a des choses, monsieur Galanos, qu'un poète tel que vous peut comprendre. Venez avec nous, si vous voulez.

${ }^{10}$ Les mots connaissent toutes les histoires, mais ils les oublient. Ils savent déjà tout de ce que nous écrivons. Nous ne faisons que rafraîchir la mémoire des mots.

${ }^{11}$ Qu'est-ce que je vais faire si ma liaison avec Marguerite s'arrête au milieu du premier chapitre, ou même à la fin du deuxième? Devrais-je trouver une autre héroïne? Je n'ai pas de sujet.
}

Anu. Lit., Florianópolis, v. 19, n. 2, p. 9-23, 2014. ISSNe 2175-7917 
Não tenho muita imaginação, isso é um fato. Eu devo a você [Marguerite] várias passagens do meu livro, devo também um bom número delas a Eckermann. Pego ideias emprestadas dos livros que li, uso falas de minha tia Persi, de meu pai, de Eléni, de nossos compatriotas que vivem na Austrália, cito até as duas mulheres que você viu na praia. Definitivamente, escrevo um livro que tem pouco de mim. ${ }^{12}$ (ALEXAKIS, 1999, p. 226)

O documentarista organiza trechos de discursos orais e escritos, tentando dar forma ao texto que vai assinar e ao qual atribuirá o gênero romance. (ALEXAKIS, 1999, p. 119) A insatisfação com o resultado de sua escrita está relacionada com a não realização do projeto inicial, com a sua não transformação em autor, pelo menos no que ele entende ser um autor.

Ao projeto de escrita de si funde-se outro, o de escrever como Eckermann. Ao falar de seu texto para seu escritor-fetiche, o narrador afirma que seu livro tem apenas três personagens: ele mesmo, Marguerite e o próprio Eckermann. Esse outro desejo latente - ser (como) Eckermann - constitui o segundo fio que se entrelaça ao primeiro para formar o texto.

A presença de Eckermann reproduz um mecanismo de legitimação relativamente usual para os escritores iniciantes. Apresentado como um autor conhecido e com alguns romances publicados, Eckermann serve de modelo e de avaliador: em vários momentos o narrador imagina o que ele diria se lesse seu texto. A opinião do escritor consagrado é, assim, decisiva para que o iniciante acredite que seu texto vai se tornar um romance. Mas essa apreciação positiva também se constitui como um argumento de autoridade que avaliza essa produção diante dos outros: o escritor que já ocupa uma posição no campo literário reconhece um par que, por sê-lo, também pode fazer parte desse campo.

A presença de Eckermann é, pois, um dos principais elementos de validação da cena de enunciação de Le Coeur de Marguerite. Dominique Maingueneau descreve assim esse processo:

A obra se enuncia através de uma situação que não é um quadro preestabelecido e fixo, ela pressupõe uma cena de fala determinada que precisa validar por meio de seu próprio enunciado. Ela se legitima através de um circuito: mediante o mundo que instaura, ela precisa justificar tacitamente a cena de enunciação que impõe desde o começo. (MAINGUENEAU, 2006, p. 55)

No texto de Alexakis, essa cena reproduz, em uma construção especular, a escrita de um romance. Além disso, o personagem escritor - e nesse caso, um escritor consagrado também revitaliza a figura do autor, tornando-o visível no tecido ficcional. Dessa forma, seu papel e suas possibilidades de atuação são problematizados na própria ficção.

\footnotetext{
${ }^{12}$ Je n'ai pas beaucoup d'imagination, c'est un fait. Je te dois plusieurs passages de mon livre, j'en dois aussi un certain nombre à Eckermann. J'emprunte des idées aux livres que j'ai lus, j'utilise les propos de ma tante Persi, de mon père, d'Eléni, de nos compatriotes qui vivent en Australie, je cite même les deux femmes que tu as vues sur la plage. En définitive, j'écris un livre qui ne me doit pas grand-chose.
} 
A escolha do nome Eckermann - que, como vimos, não é arbitrária - traz ainda outra questão que merece ser discutida. Charline Pluvinet, analisando alguns personagens escritores, afirma:

Os personagens de escritor ficam assim em um duplo movimento simétrico entre ficção e realidade: os autores da história literária se desrealizam na ficção enquanto os autores imaginários ganham em verossimilhança histórica, como se seu estatuto referencial respectivo tendesse a uma inversão. ${ }^{13}$ (PLUVINET, 2012, p. 141)

Eckermann se instala, entretanto, entre a ficção e a realidade. O Eckermann histórico era poeta e secretário de Goethe. Seu texto mais conhecido é justamente aquele em que reproduz seus diálogos com Goethe, o escritor consagrado. Em Le Coeur de Marguerite, cuja ação se desenrola na atualidade, Eckermann troca de posição: ele é o escritor famoso e seu admirador transcreve em seu romance trechos dos diálogos imaginários e reais que tiveram. Essa mudança de posição indica uma instabilidade no lugar ocupado pelo autor: sua presença como elemento da ficção o tira de trás da pena e o coloca no espaço ficcional.

O Eckermann de Alexakis provoca uma oscilação entre fictício e histórico que constrói uma ironia (HUTCHEON, 2000, p. 92-93) e, principalmente, mistura os termos do contrato de leitura: o leitor se vê diante de um personagem escritor inverossimelmente histórico e somente no fim do texto confirmará a hipótese de tratar-se de um simples homônimo. Esse embaralhamento de pistas contribui para destacar o papel do autor no texto literário.

\section{Duplamente fictício}

Pseudo (1976) é um exemplo particularmente complexo de configuração da figura do autor. Assinado por Émile Ajar no momento de sua publicação, o livro, sem nenhuma indicação de gênero, apresenta um contrato de leitura autobiográfico. $\mathrm{O}$ autor, que ganhara o prêmio Goncourt no ano anterior com seu segundo romance, La Vie devant soi (1975), é suspeito de ser, na verdade, um disfarce de Romain Gary, escritor conhecido e autor de uma obra de mais de vinte volumes. A dúvida se baseia em dois fatos: em primeiro lugar, o texto de estreia de Émile Ajar gerou desconfianças quanto à identidade do autor, pois foi considerado um trabalho árduo de escrita e, por isso, dificilmente produzido por um novato; em segundo lugar, o indivíduo que se apresentou como Émile Ajar, cujo nome verdadeiro é Paul Pavlowitch, era primo em segundo grau de Romain Gary. A publicação de Pseudo busca

\footnotetext{
${ }^{13}$ Les personnages d'écrivain sont ainsi pris dans un double mouvement symétrique entre fiction et réalité: les auteurs de l'histoire littéraire se déréalisent dans la fiction tandis que les auteurs imaginaires gagnent en vraissemblance historique, comme si leur statut référentiel respectif tendait à s'inverser.
}

Anu. Lit., Florianópolis, v. 19, n. 2, p. 9-23, 2014. ISSNe 2175-7917 
e consegue dirimir as dúvidas e provar a existência de Émile Ajar. Em 1980, após o suicído de Romain Gary, o texto póstumo, Vie et mort d'Émile Ajar, reabre o caso e apresenta as provas de que Émile Ajar era de fato um pseudônimo de Romain Gary.

A opção por um pseudônimo pode ter motivações diversas e suas implicações, no campo literário, podem ser fundamentais para a construção dos sentidos do texto. O caso de Romain Gary/Émile Ajar é especialmente emblemático, já que nenhum desses nomes corresponde a uma certidão de nascimento ${ }^{14}$. Segundo David Martens, o pseudônimo pode ser lido como a "assinatura de um ser ficcional" (MARTEENS apud PLUVINET, 2012, p. 75), o que, realmente, corresponde ao estatuto de Ajar. Assim, o nome que consta na capa do livro e que supostamente se responsabiliza pelo texto, na verdade produz uma outra dimensão ficcional: os adjetivos atribuídos a Émile Ajar e a seu texto por leitores profissionais e amadores remetem a uma ausência, a um escritor que não existe ou que talvez exista como resultado de um desdobramento autoral pouco comum ou resultante de um caso de dupla personalidade. A existência desse ausente será atestada através de um texto autobiográfico em que delírios e transtornos de comportamento são narrados e usados como provas de diferença e de autoria.

A autobiografia - e as escritas de si em geral - recoloca a figura do autor no centro das atenções do leitor, na medida em que este tem a expectativa de encontrar referências a quem assina o texto. Philippe Lejeune afirma que "as formas do pacto autobiográfico são muito diversas, mas todas elas manifestam a intenção de honrar sua assinatura." (LEJEUNE, 2008, p. 26) Em relação a Pseudo, essa afirmação é pertinente e, por isso mesmo, ambígua. De fato, o autor tenta garantir uma referencialidade ancorada nas histórias de vida de Romain Gary e Paul Pavlowitch, comprovando assim sua veracidade. Mas a assinatura de Émile Ajar sempre foi uma ficção e, dessa forma, "honrá-la" significa permanecer na ficção.

Philippe Lejeune considera a possibilidade de uma autobiografia ser "inexata" e de uma ficção autobiográfica ser "exata", mas salienta que:

A importância do contrato pode ser, aliás, comprovada pela própria atitude do leitor
que é determinada por ele: se a identidade não for afirmada (caso da ficção), o leitor
procurará estabelecer semelhanças, apesar do que diz o autor; se for afirmada (caso
da autobiografia), a tendência será tentar buscar as diferenças (erros, deformações
etc.). (LEJEUNE, 2008, p. 26)

Buscando convencer o leitor de sua veracidade, Ajar se apresenta como um indivíduo desequilibrado, que narra sua internação em uma clínica psiquiátrica em Copenhague.

\footnotetext{
${ }^{14} \mathrm{O}$ verdadeiro nome de Romain Gary é Roman Kacew. A solicitação de modificação de nome foi autorizada por um decreto do Conselho de Estado, de 9 de outubro de 1951. (BONA, 1987, p. 43)
} 
Trechos de seu prontuário - que ele teria roubado -, narrativas delirantes - que confirmam seu desequilíbrio -, o drama de seu nascimento como escritor e referências a Romain Gary são alguns aspectos do texto que contribuem para dar credibilidade à autobiografia.

Ainda nesse sentido, desde o início, podemos reconhecer uma estratégia fundamental - e ajarianamente desesperada - para comprovar sua existência: o ataque explícito e feroz a Romain Gary, tratado por Ajar como Tonton Macoute ${ }^{15}$ :

Tonton Macoute é um canalha, mas isso não quer dizer necessariamente que ele é meu pai. Eu nunca pretendi isso, apenas desejei que fosse, em alguns momentos, por desespero. Não sou eu, são meus investigadores que insinuaram, depois da publicação do meu livro La Vie devant soi, que ele era meu verdadeiro autor. ${ }^{16}$ (GARY, 1976, p. 10)

Aos olhos do leitor, a agressividade exacerbada em relação ao parente a quem é atribuída a autoria de seus livros é justificada pelo risco que corria o autor de ser desapossado de sua criação literária. Mas, além disso, o estilo de Pseudo corresponde, com as ressalvas do exagero, ao dos romances Gros-Câlin (1974) e La Vie devant soi (1975), textos anteriores de Ajar. Pierre Bayard destaca essa semelhança:

Em Pseudo, efetivamente, que funciona de certa forma em díptico com Vie et mort d'Émile Ajar (à autobiografia do escritor falecido responde a do autor que nunca existiu), Gary conseguiu se aproximar muito de uma verdadeira escrita da psicose. Como nos dois primeiros livros assinados por Ajar, a linguagem é esfacelada, mas através de uma desordem de natureza diferente, que visa mais profundamente as próprias fontes do mecanismo do pensamento. ${ }^{17}$ (BAYARD, 1990, p. 111)

Nesse jogo vertiginoso de espelhos, Romain Gary transforma a pena de Ajar em lâmina afiada que ataca o próprio Gary. Contudo, assim como nas ilusões criadas em espelhos sempre há, pelo menos, uma imagem verdadeira, da mesma forma, em Pseudo, a voz atribuída a Ajar enuncia a verdade, afirmando que não existe. O leitor, todavia, interpreta esse enunciado como um ajarismo que confirma a existência do autor.

\footnotetext{
${ }^{15}$ Tonton Macoute é a forma como se referiam os haitianos aos membros da força paramilitar criada pelo ditador François Duvalier, o Papa Doc, no fim dos anos 1950. O nome se refere a um personagem do folclore haitiano que representa um homem que anda com uma sacola e leva as crianças que se comportam mal. Os Tonton Macoute de Duvalier ficaram conhecidos pela extrema violência com que combatiam os que se opunham ao ditador e pelos abusos que visavam intimidar o povo.

${ }^{16}$ Tonton Macoute est un salaud, mais cela ne veut pas dire nécessairement qu'il est mon père. Je ne l'ai jamais prétendu, je l'ai seulement espéré, à certains moments, par désespoir. Ce n'est pas moi, ce sont mes investigateurs qui ont insinué, après la publication de mon livre La Vie devant soi, qu'il était mon véritable auteur.

${ }^{17}$ Dans Pseudo en effet, qui fonctionne un peu en dyptique avec Vie et mort d'Émile Ajar (à l'autobigraphie de l'écrivain qui n'est plus répond celle de l'auteur qui n'a jamais existé), Gary est parvenu à s'approcher très près d'une véritable écriture de la psychose. Comme dans les deux premiers livres signés Ajar, le langage est mis en pièces, mais selon un dérèglement de nature différente, qui s'attaque de façon plus profonde aux sources mêmes du mécanisme de la pensée.
}

Anu. Lit., Florianópolis, v. 19, n. 2, p. 9-23, 2014. ISSNe 2175-7917 
Em vários trechos, a escrita com duplo sentido expõe a verdade e mantém a farsa, como por exemplo: "Eu não sei porque o [Tonton Macoute] castigava tempo todo. Talvez porque seja preciso realmente se contentar com o pseudo-pseudo. $\mathrm{O}$ verdadeiro responsável brilha por sua ausência. Então, procura-se um, mais acessível. ${ }^{, 18}$ (GARY, 1976, p. 104-105) Ou ainda:

Eu pedi que fosse instalada uma secretária eletrônica. Um dispositivo moderno, civilizado e especialmente previsto para esse objetivo, que respondia que eu não existia, que não havia Paul Pavlowitch, eu era uma mistificação, um embuste, eu não era desse tipo. Eu apresentava evidentemente alguns sinais exteriores de existência, mas era literatura. ${ }^{19}$ (GARY, 1976, p. 24)

Em Pseudo, os dois escritores participam de uma cena de enunciação que cria um efeito de presença do autor. Émile Ajar, o escritor que não é, tenta provar que é o autor dos livros que assinou, enquanto Romain Gary, o escritor que é, se autorrepresenta como o autor que não é, que não escreveu os livros assinados por Ajar. De ambos os lados, o retorno do autor é axiomático.

O desespero demonstrado por Ajar em Pseudo também confirma uma postura: o escritor iniciante não quer ser confundido nem associado ao escritor consagrado. Contrariamente ao narrador anônimo de Le Coeur de Marguerite, que busca o apoio de Eckermann para confirmar seu texto, Ajar se esforça para garantir o distanciamento e contesta qualquer semelhança com Gary. Num momento de irritação particularmente aguda, reafirma: “Eu sou Émile Ajar! gritava, batendo no peito. O único! Sou o filho de minhas obras e o pai das mesmas! Sou meu próprio filho e meu próprio pai! Não devo nada a ninguém! Sou meu próprio autor e me orgulho disso!"20 (p. 192-193)

Essa postura de Émile Ajar é a única possível para assegurar sua presença e impor a ausência de Romain Gary. Em Pseudo, o apagamento do escritor e o fortalecimento do golem (ROBIN, 1997) reconfiguram sentidos para o autor em meio aos fios do texto, borrando os espaços entre fictício e real.

\footnotetext{
${ }^{18}$ Je ne sais pas pourquoi je le punissais tout le temps. Peut-être parce qu'il faut bien se contenter du pseudopseudo. Le vrai responsable brille par son absence. Alors, on en cherche un, plus accessible.

${ }_{19}$ J'ai fait mettre un répondeur automatique. Un gadget moderne, civilisé et spécialement prévu dans ce but, qui répondait que je n'existais pas, qu'il n'y avait pas de Pavlowitch, j'étais une mystification, un canular, je n'étais pas du genre. Je présentais évidemment certains signes extérieurs d'existence, mais c'était de la littérature.

${ }^{20}$ Je suis Émile Ajar! hurlais-je, en me frappant la poitrine. Le seul, l'unique! Je suis le fils de mes oeuvres et le père des mêmes! Je suis mon propre fils et mon propre père! Je ne dois rien à personne! Je suis mon propre auteur et j'en suis fier!
} 


\section{Configurações do autor}

O personagem escritor representa, em um leque de gradações, a presença do autor no espaço ficcional. Essa presença, sem resgatar a autoridade autoral, recoloca o foco de estudo no fazer literário e expõe diferentes configurações do sujeito que se apresenta como autor. Configuração parece ser a palavra mais apropriada para descrever esse movimento. Originária do latim, teve seu uso ampliado, no fim do século XX, sobretudo, na informática. Em seu sentido original, indica a ação de dar forma, de assemelhar na figura (HOUAISS, 2001, p. 796). Na acepção mais recente, nomeia a ação de ajustar ou definir parâmetros em um sistema informático ou em um equipamento.

Os personagens de escritor são construídos a partir de assemelhações a figuras diferentes. No corpus que propusemos neste texto, identificamos o escritor desejado e exemplo ideal a ser seguido, o escritor iniciante em crise diante da folha de papel, o escritor fantasma que assombra com seu (re)nome o jovem promissor, o escritor psicótico que se autoretrata. Essas figuras de escritores são não apenas verossímeis, mas verdadeiras, na medida em que, sem terem sido construídas a partir de modelos identificados - mesmo Gary e Ajar, em Pseudo, escapam à cópia - são reconhecíveis, ou seja, o leitor pode associá-las a indivíduos reais.

O personagem escritor também é responsável por um ajuste em algumas características do texto. Referimo-nos especialmente à revisão de papéis - o autor passa a fazer parte do tecido, tornando-se visível e fictício - e à construção de sentidos do texto. $\mathrm{Na}$ produção literária contemporânea que tem como mecânica a autorreflexividade, o personagem escritor promove, de certa forma, a revanche de um exilado. Ao focalizar o produto e desapossar o autor do sentido original, a crítica estruturalista limitou as possibilidades de participação deste em sua obra. As escritas de si, que se multiplicaram extraordinariamente a partir dos anos 1980 (FIGUEIREDO, 2013, p. 13), e a recorrência do personagem escritor na ficção contemporânea integram, explícita ou implicitamente, a voz do autor no texto.

Como destaca Charline Pluvinet (2012) "a representação ficional do autor não se contenta em evocar sua arte literária ou suas teorias estéticas, mas se demora em sua pessoa, sua figura social e moral e até mesmo em sua intimidade, sem hesitar em trazer à luz atos sem glória e fatos ocultos."21 (PLUVINET, 2012, p. 200) Dessa forma, as três instâncias do auctor

\footnotetext{
${ }^{21} \mathrm{La}$ représentation fictionnelle de l'auteur ne se contente pas d'évoquer son art littéraire ou ses théories esthétiques mais s'attarde sur sa personne, sa figure sociale et morale voire son intimité, sans hésiter à porter au jour des actes sans gloire et des faits cachés.
}

Anu. Lit., Florianópolis, v. 19, n. 2, p. 9-23, 2014. ISSNe 2175-7917 
- a pessoa, o escritor e o inscritor - identificadas por Maingueneau se confundem não no nó borromeano proposto pelo linguista, mas no personagem escritor.

Fictício - como Ajar -, fictício com referências históricas - como Eckermann -, histórico fíccionalizado - como Gary em Pseudo -, espécime fictício - como o iniciante anônimo em Le Coeur de Marguerite -, o autor assume diferentes avatares no espaço ficcional e se mostra claramente ao leitor. Charles Dantzig, em seu Dictionnaire égoïste de la littérature française, no verbete "Auteurs", propõe uma descrição pertinente da ficcionalização do autor. Diz o poeta, romancista, ensaísta e tradutor:

\begin{abstract}
Um livro é mais do que seu autor. De certa forma, seria mais exato publicar livros sem nome. Ou então: "Um livro de... em companhia de seus fantasmas." O livro mais bem feito é aquele na entrada do qual se poderia pendurar o cartaz:

O AUTOR ESTÁ AUSENTE

Mas é impossível. [...]

Apesar de termos dado a palavra a nosso eu ideal, sempre é preciso que, no fim, subrepticiamente, apareça, sorridente, insinuante, pegajoso, ali, um indivíduo. A literatura é impura. ${ }^{22}$ (DANTZIG, 2005, p. 60-62).
\end{abstract}

\title{
Referências
}

ALEXAKIS, Vassilis. Le coeur de Marguerite. Paris: Stock, 1999.

BARTHES, Roland. La mort de l'auteur (1968). In: Le bruissement de la langue. Paris: Seuil, 1984.

O prazer do texto. Tradução J. Guinsburg. São Paulo: Perspectiva, 1996. [1973 para a edição original]

BAYARD, Pierre. Il était deux fois Romain Gary. Paris: PUF, 1990.

BESSY, Marianne. Vassilis Alexakis. Exorciser l'exil. Amsterdam/New York: Editions Rodopi, 2011.

BONA, Dominique. Romain Gary. Paris: Mercure de France, 1987.

COMPAGNON, Antoine. $O$ demônio da teoria. Trad. Cleonice P. B. Mourão. Belo Horizonte: Ed. UFMG, 2012. [1998 para a edição original]

DANTZIG, Charles. Dictionnaire égoïste de la langue française. Paris: Grasset et Fasquelle, 2005. (Coll. Le Livre de Poche)

\footnotetext{
${ }^{22}$ Un livre, c'est plus que son auteur. D'une certaine façon, il serait plus exact de publier les livres sans nom. Ou alors: "Un livre de ... en compagnie de ses fantômes." Le livre le plus réussi est celui à l'entrée duquel on pourrait suspendre la pancarte:

L'AUTEUR EST ABSENT

Et c'est impossible. [...]

Nous avons beau laisser la parole à notre moi idéal, il faut toujours que, à la fin, subrepticement, apparaisse, souriant, insinuant, glaireux, là, un individu. La littérature est impure.
}

Anu. Lit., Florianópolis, v. 19, n. 2, p. 9-23, 2014. ISSNe 2175-7917 
ECKERMANN, Johann Peter; GOETHE, Johann Wolfgang von. Conversações de Goethe com Eckermann. Trad. de Luís Silveira. Porto: Livraria Tavares Martins, 1947.

FIGUEIREDO, Eurídice. Mulheres ao espelho. Autobiografia, ficção, autoficção. Rio de Janeiro: EdUFF, 2013.

FOUCAULT, Michel. O que é um autor? In: Ditos e Escritos III. Estética: Literatura e Pintura, Música e Cinema. Organização e seleção de textos de Manoel Barros da Motta. Tradução de Inês Autran Dourado Barbosa. Rio de Janeiro: Forense Universitária, 2009.

GARY, Romain. Pseudo. Paris: Mercure de France, 1976.

HOUAISS, Antonio; VILLAR, Mauro de Salles (Org.). Dicionário Houaiss da Língua Portuguesa. Rio de Janeiro: Objetiva, 2001.

HUTCHEON, Linda. Teoria e politica da ironia. Trad. de Julio Jeha. Belo Horizonte: Editora da UFMG, 2000.

LEJEUNE, Philppe. O pacto autobiográfico: de Rousseau à Internet. Belo Horizonte: Editora UFMG, 2008.

MAINGUENEAU, Dominique. Discurso literário. Trad. de Adail Sobral. São Paulo: Contexto, 2006.

. Autor - A noção de autor em análise do discurso. Trad. Helena Nagamine Brandão. In: POSSENTI, Sírio; SOUSA-E-SILVA, Maria Cecília Perez. (Org.) Doze conceitos em análise do discurso. São Paulo: Parábola, 2010, p. 25-47.

Imagem de autor - não há autor sem imagem. Trad. Adail Sobral. In: POSSENTI, Sírio; SOUSA-E-SILVA, Maria Cecília Perez. (Org.) Doze conceitos em análise do discurso. Tradução de Adail Sobral et alii. São Paulo: Parábola, 2010b, p. 139-156.

MEIZOZ, Jérôme. Postures littéraires. Mises en scène modernes de l'auteur. Genève: Slatkine, 2007.

PLUVINET, Charline. Fictions en quête d'auteur. Rennes: Presses Universitaires de Rennes, 2012.

ROBIN, Régine. Le Golem de l'écriture. De l'autofiction au Cybersoi. Montréal, XYZ, 1997.

[Recebido em fevereiro de 2014 e aceito para publicação em agosto de 2014]

\section{Fiction by fictitious writers}

Abstract: The author has been an object of study ever since his existence was acknowledged. In time, his role in society and in the production of the literary text have been treated differently. In the second half of the 20th century, his death was considered a necessary step for the text to open up to different meanings constructed by the reader. Even though the notion of authorship never disappeared, in contemporary literature we can notice the presence of the author in the text in the role of authors-characters. Among the different ways this presence can be seen, we can highlight two that share the fictitious nature, but follow highly distinct paths throughout the text: Eckerman, in Le Coeur de Marguerite (1999), by Vassilis 
Alexakis, and Émile Ajar, in Pseudo (1976), by Romain Gary. Changed into an element of fiction, the author acquires new meanings and sheds new light on the discussion about the author.

Keywords: Vassilis Alexakis. Romain Gary. Author. Contemporary fiction.

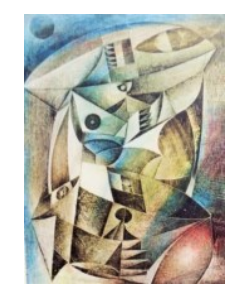

